\title{
Tax Evasion and Governance Challeneges in the Nigerian Informal Sector
}

\author{
SANI SAIDU ${ }^{1, *}$, UMAR DAUDA $^{2}$ \\ ${ }^{1}$ Aberdeen Business School, Robert Gordon University, United Kingdom \\ ${ }^{2}$ Debt Management Agency, Bauchi State, Nigeria \\ *Corresponding author: S.SAIDU@RGU.AC.Uk
}

Received May 26, 2014; Revised June 11, 2014; Accepted July 13, 2014

\begin{abstract}
Tax evasion has been an issue of concern in the Nigerian tax system for decades. Tax evading attitude is argued to have an adverse effect on government's socio-economic and political programs.Many commentators and analyst blamed the situation on the tax authorities, for not living up to expectation with regards to tax administration; others attribute the case to the unpatriotic attitude of the taxpayers. In light of these contending positions, this study therefore, assessed the operation of the informal sector in Bauchi State of Nigeria, where tax evasion assumed to be a normal practice due to high level of informalities in the conduct of businesses within the sector. Primary and secondary data were collected and analyzed. Spearman rank order correlation test was employed to test the relationship between ethics of tax evasion and performance of government and the rho ( $\mathrm{r}$ ) value was fortified in assessing the extent of the relationship. The study findings reveal among other findings that, although its ethical to pay tax but individuals refuse to, due to bad governance and other factors (religious, political and socio cultural) and high level of illiteracy to some extent. It was recommended therefore, a deliberate and more aggressive public enlightenment campaign be embarked upon by the state government on the importance of taxes economically and otherwise.
\end{abstract}

Keywords: governance, informal sector, tax evasion

Cite This Article: SANI SAIDU, and UMAR DAUDA, "Tax Evasion and Governance Challeneges in the Nigerian Informal Sector.” Journal of Finance and Economics, vol. 2, no. 5 (2014): 156-161. doi: 10.12691/jfe-2$5-4$.

\section{Introduction}

Tax is a civic contribution imposed by the government on her subject (individuals and corporate bodies) with a view to finance its core responsibilities of ensuring optimum public welfare socially, economically and politically (Kiable and Nwankwo, 2009). A number of challenges were reported to have hindered effective administration of tax system in many states around the globe. In particular, tax evasion is argued to be the most challenging practice in developing countries such as Nigeria. Tax evasion is described by Olayinka et al (2010) as an intentional illegal behavior involving a direct violation of tax laws to avoid payment of taxes. The phenomenon of tax evasion is found in all societies (countries), indeed, no matter the control measures put in place, some people maneuver their ways and break government's rules and regulations relating taxes. The practice of maneuvering tax laws is considered illegal which needs to be checked and addressed by the relevant authorities. Indeed, government's awakening efforts to addressing tax evasion became necessary for many reasons, including, enhancing government's revenue, regulating macroeconomic variables, redistributing inequality of income and other benefits derivable from a good tax system (Dandago and Alabede, 2000). In fact, a good tax system is said to be an instrument for regulating and stabilizing erected behaviors in an economy (Ezeoha and Ogamba, 2010 and Toby, 1983). Equally, tax has been argued to be a significant tool of government fiscal policy via increase or decrease of various rates of taxes depending on macroeconomics situation (Kiabel and Nwankwo, 2009). Engagement with literature on Nigerian tax systems showed that the authorities responsible for managing taxes have not been transparent neither appropriately accounts for the accrued revue in an open manner (Olayinka et al., 2010). This has been a global phenomenon as evidence shows that accountants and tax professionals who are expected to promote transparency of the practices and detect fraud use their expertise to facilitate tax evasion (Sikka and Willmott, 2010; Ezeoha and Ogamba, 2010 and Sikka, 2008). No doubt, even in Nigeria, the nontransparent attitude of tax professionals, accountants and other stakeholders exposes the weaknesses of the tax system in the country(Eigen, 2002). Hence, this paper has been divided into eight segments. Section 2 gave an account of tax evasion and rule of law in Nigeria. In Section 3 Nigerian informal sector and tax challenges is discussed. Sections 4 and 5 discuss research question and methodology respectively. In Sections 6 and 7 discussion of analysis and hypothesis respectively are presented. Lastly, Section 8 concludes the paper. 


\section{Tax Evasion in Nigerian Economy}

Tax evasion has been defined by Soyode and Kajola (2006) as deliberate and willful practice of not disclosing full taxable income in order to pay less tax. This behavior is portrayed as criminal act of violating the provision of tax laws which will eventually lead to reduction in total government revenue (Kay, 1980). Hence, in general, paying less tax or not at all than what one is legally obliged to, described the concept of tax evasion. Eboziegbe (2007) posited that the act of tax evasion remained one of themost serious threatsto the revenue and indeed entire economy of the Nation.Feld and Frey (2002) asserted that in most cases tax evasion arises in a situation where a taxpayer arranges his financial affairs in a way that would make him not to pay or pay the least possible amount of tax by infringing the legal rules. Faruyola (1987) is of the opinion that tax evasion can be accomplished through deliberate act of omission or commission which might include: Failure to pay tax, failure to submit returns, omission or misstatement of items return intentionally, claiming relief in personal income tax which do not exist, understating income, documenting fictitious transactions, overstating expenses and/or failure to answer queries. Although these acts are more or less ways through which tax evasion are perpetrated but in themselves constitute criminal act under tax laws and of all these failure to render tax returns is the most common form found in Nigeria (Kiabel and Nwankwo, 2009). Different circumstances cause tax evasion, as Kiabel (2001) argued, some businessmen do not see rationale for paying tax irrespective of the huge profit they might have made. They prefer to make up their account in such a way that a loss will be reflected. This is not an exception in Nigeria; Onuigbo (1986) listed some determinants why people may be reluctant to disclose their actual income and pay tax, which include:

i) Inequitable distribution of amenities

ii) Misuse or mismanagement of tax revenue.

iii) Inability of government/tax authority to censuses the actual taxpayers and serve them with assessment notice and

iv) Lack of civic-spirit responsibility from the public.

Analyst reiterated the problem of tax evasion as a common practice especially amongst self-employed business men of Nigeria (Ayua, 1999). This position has been argued within the Nation as it opined that only civil servants, salaried workers and few self-employed constitute class of people that actually pays tax in Nigeria (Ayua, 1999). Indeed, Ayua (1999) argued that even among the salaried workers many have turned the statutory personal allowances and relief into a fertile ground for tax evasion because record has shown that almost all Nigerians are married with at least four children.

\subsection{Tax Evasion and Rule of Law}

Respecting rule of law is one of the obligations of every good citizen of a country. However, governments have a bigger obligation to ensure that those laws are respected and followed. In case of tax collection and administration, authorities are obliged to ensure taxes are properly paid and evaders are bringing to book (Schneider and Enste, 2002 and Brunetti and Wader, 2003). Supporting this view earlier, Kiabel (2001) posited that tax evasion became rampant in Nigeria because there is little or no legal enforcement in place and indeed, weak and arbitrary enforcement of tax laws encourage the evader and fraud starts. Nwachukwu (2006) further stressed that the only way to reduce tax evasion and corruption in developing countries is ensuring strict implementation of rule of law. Not only in Nigeria, tax evasion in most developing countries is so rampant and worsens by day due to the fact that governments have not made required effort to arresting the situation. Hence required revenue for the governance of the countries cannot be raise, these countries (developing states) often resort to borrowing public debt (both internal and external) which may not only crowd out the private sector including self-employed individuals of their economies but also lead them to debt traps (Chiuma, 2006). In similar vein, Sikka and Hampton (2005) and Olatunde (2007) identified tax evasion as one of the major social problems inhabiting development in developing countries and eroding the existing welfare nature even in developed economies of the world. This has led to a growing attention among policy makers and stakeholder across the globe to call for the intervention of law agencies within individual countries. In summary, governments and tax authorities must resort to enforcing laws for proper implementation of taxes and success of its administration.

\section{Nigerian Informal Sector and Tax Challenges}

Nigerian informal sector is described as any commercial activities from all sector of the economy that operate outside the purview of government regulation (Ekpo and Umoh, 1996). This may be visible, irregular, non-structured, backyard, underground, subterranean, unabsorbed or residual. Informal economic activities in Nigeria entails wide range of small and medium scale activities largely self-employment activities, most of them are traditional occupations and adopt traditional method of production(Boyland and Burckhardt, 2002).Others include financial intermediation and economic endeavors of subsistence nature or retail trade, transport repair services and household or other personal sources. Activities of the informal sector in Nigeria are difficult to measure. This is because they are highly dynamics but contribute substantially to the general growth of the economy. The informal sector contributes significantly to national economy in terms of output and employment. The government must therefore encourage and empower their activities through the provision of conducive environment and policies to enhance their operations (Alm and Martinez, 2008). The informal sector has no tendency to be missed out, it must therefore be sustained for optimal contribution to the growth of the economy. In response to this, the Nigerian government have attempted severally to positively impact on the operation of informal sector like family economic advancement programme (FEAP) in 1997 whose objective is to serve as a catalyst to stimulate and encourage the growth of informal sector, capacity building and credit support through peoples bank. Entrepreneurship development policy has also been implemented in late 80s. This programme through 
National Directorate of Employment (NDE) has attempted to provide good framework for small and medium enterprises (SMES) activities. However, there are series of international financial assistance e.g. from African Development Bank (ADB), World Bank and United Nation Development Programme (UNDP) to the activities of SMEs in Nigeria. In 1999, Nigerian government released about 8 Billion Naira through the initiative of the then President Obasanjo; Small and Medium Enterprises Development Agency (SMEDAN) to enhance accessibility of soft facility for smooth running of SME activities (Norman, 1999). In fact, preliminary investigations showed that the Nigerian government continue with these programs and support to the informal sector. Now, what's left for the government is how to convince people in the informal sector to respect rule of law and pay their tax obligations. It is a known fact that majority of people operating in the informal sector are not elite. This, couple with several reasons given for evading taxes as discussed in section 2, as well it raises concern on the possibility of meeting obligations by both authorities and the tax payers. To operationalize these possibilities, the research questions below are developed for the study.

\section{Research Objectives}

Having seen what tax and its related environmental characteristics from the discussions in the previous sections were, this study deems it important to examine the ethics of tax evasion in the Nigerian informal sector, as informal sector contributes heavily in declining of revenue from personal income tax in Nigeria(Kiabel and Nwankwo, 2009 and Nwachukwu, 2006).

The paper therefore, attempts to find answer to the following specific questions:

1. Does demographic data affect individual perceptions /desires on a particular phenomenon?

2. What factors influence or encourage tax evasion in Nigeria?

3. What are the factors discouraging potential tax payers from filling returns to the relevant tax authorities?

4. How tax evader manages to operate in an economy of developing countries in matters relating official issues like Nigeria?

5. How can government eliminate or at least minimize tax evasion among self-employed individuals?

6. Can personal income tax from self-employed individuals if properly utilized be considered as mainstay of government revenue?

To address the above questions an appropriate methodology was adopted and discuss in the following section.

\section{Research Methodology}

Primary and secondary data were collected for the study. The primary data collection instrument is mainly personal interview supported with few questionnaires. The interview was conducted with self-employed individuals such as traders, transporters and other people carrying out menial jobs within the society. On the other hand, secondary data were collected through content analysis of journals, textbooks, bulletin obtained through library and internet as well as few incomplete records of some businesses covered by the study. Mainly, the population of this study consists of 1000 self-employed individuals registered with different associations within Katagum Zone in Bauchi State of Nigeria. For simplicity, this population is conveniently divided into four categories in accordance with their business undertakings: trade, transport, provision of portable water on commercial basis and others (which represent occupations not listed above). 200 individuals were selected using the categories as strata, thus warranting the use of stratified (applied random) sampling method. Fifty individuals were chosen randomly from each stratum. This sampling technique was chosen as it allows further representativeness in selecting sample from the population. Personal interview was then conducted with these respondents in groups and isolation. The schedule of the interview is meant to determine the perception on tax evasion and to assess whether performance of government influences the view of the respondents. The study heavily depends on direct interview for two (2) main reasons, firstly, most of the respondents cannot read and interpret a structured questionnaire, and hence information can better be obtained from such respondents through interview. Secondly, due to tight schedule and business engagements of self-employed individuals as opined by Uvima (2009), the researcher decided that, the limited time allowed should rather be utilized in direct contact with them so as to grasp a lot of information as reliable as it may be from the source followed with cautious tactics to confirm reliability and validity of data.

Results of this research are presented in the next section using simple percentages followed by discussions under each table. Finally spearman rank order correlation test was employed to test the presence or absence of relationship between ethics of tax evasion and performance of government. Student t-test was later employed to fortify the rho (r) value so as to assess the extent of the relationship if any. Hence two hypotheses were formulated for this purpose:

$\mathrm{H}_{1}$ : Government performance has significant influence on the ethics of tax evasion

$\mathrm{H}_{0}$ : Ethics of tax evasion was not significantly influenced by government performance.

\section{Result and Discussion}

As mentioned earlier in the preceding section, the study heavily depends on the interviews (180) and few questionnaires administered (20). Hence, results from this survey are presented in tables below and discussions under each table respectively.

\begin{tabular}{|c|c|c|c|c|}
\hline Table 1. AGE AND GENDER \\
\hline \multirow{2}{*}{ Responses } & \multirow{2}{*}{ Respondents } & \multirow{2}{*}{$\%$} & \multicolumn{2}{|c|}{ Gender } \\
\cline { 3 - 5 } & & & $\mathrm{M}$ & $\mathrm{F}$ \\
\hline Below 20yrs & 20 & 10 & 20 & 0 \\
\hline $20-50$ yrs & 130 & 65 & 105 & 25 \\
\hline Above 50yrs & 50 & 25 & 45 & 5 \\
\hline Total & $\mathbf{2 0 0}$ & $\mathbf{1 0 0} \%$ & $\mathbf{1 7 0}$ & $\mathbf{3 0}$ \\
\hline
\end{tabular}

Source: Author Generated. 
It can be deduced from the above table that most of the self-employed surveyed are youth between the ages of 2050years as they formed more than 60 percent of the sample. This clearly shows that they will be more active and ambitions to acquire and gain wealth. This is because that range is a transitional stage from dependent to independent and shouldering responsibilities of others. The table also shows low level of female participation in Nigerian informal business sector. Of course that $10 \%$ of below 20years has implications in an economy indicated in the table below (Educational background) because more than $90 \%$ of this $10 \%$ who should have been in schools were not fortunate to get at least hold a minimum certificate. Indeed, very few were able to scaled through post primary education. Lastly, 25\% of the respondents aged 50 years and above, arguably, this category had the required maturity in taking a stand on critical issue.

Table 2. EDUCATIONAL BACKGROUND

\begin{tabular}{|c|c|c|}
\hline & Responses & $\mathbf{\%}$ \\
\hline Basic & 120 & 60 \\
\hline Post basic & 65 & 32.5 \\
\hline Graduate/post graduate & 15 & 7.5 \\
\hline Total & $\mathbf{2 0 0}$ & $\mathbf{1 0 0 \%}$ \\
\hline Source: Author Generated
\end{tabular}

The above table presented the level of education attained by the respondents and it clearly shows high level of illiteracy inherent in the sampled self-employed individuals. Discussion on its implication has started in the previous table. Moreover, these implications have hugely contributed in their attitude of not paying tax at all instead of taking tax avoidance tactics. However, it is important to revealed that all the 15 respondents in the third category (Graduate/post graduate) are between the age of $20-50$, while 19 out of that 120 in the first category falls below the age of 20 .

Table 3. CAPITAL - BASE OF THE RESPONDENTS IN FINANCIAL VALUES

\begin{tabular}{|c|c|c|}
\hline Responses & Respondents & $\mathbf{\%}$ \\
\hline Less than N1m & 10 & 5 \\
\hline $1-\mathrm{N} 10 \mathrm{~m}$ & 50 & 25 \\
\hline Above $10 \mathrm{~m}$ & 140 & 70 \\
\hline Total & $\mathbf{2 0 0}$ & $\mathbf{1 0 0 \%}$ \\
\hline
\end{tabular}

Source: Author Generated

Statistics in the above table indicates how millionaires are left out of the taxpayer's census, which eventually leads to decline in the total revenue generated more specifically from personal income tax. In fact there are about 10 transporters who claimed to have worth over $100 \mathrm{~m}$ each without paying single kobo as tax for several years in business.

Table 4. HAVE YOU EVER PAID TAX?

\begin{tabular}{|c|c|c|}
\hline Responses & Respondents & \% \\
\hline Yes & - & - \\
\hline No & 200 & 100 \\
\hline Total & $\mathbf{2 0 0}$ & $\mathbf{1 0 0 \%}$ \\
\hline
\end{tabular}

Source: Author Generated.

The results in the above table show that none of the respondents have ever paid tax despite the huge income or capital put in business which is statutorily taxable. This may be as a result of lack of seriousness and effort from the tax authority to identify, assess and collect taxes from such millionaires. On the hand, it is likely; people have not seen any essence of paying tax because governments may not tangibly accounts for the money it generates from other means of revenue.

Table 5. WHY ARE YOU NOT PAYING TAXES, DO YOU CONSIDER IT ETHICAL?

\begin{tabular}{|c|c|c|}
\hline Responses & Respondents & \% \\
\hline Ethical & 180 & 90 \\
\hline Unethical & - & - \\
\hline I don't know & 20 & 10 \\
\hline Total & $\mathbf{2 0 0}$ & $\mathbf{1 0 0 \%}$ \\
\hline
\end{tabular}

Source: Author Generated

It can be understood from the above table that almost all the respondents agreed that, is ethical to pay tax with exception of $10 \%$ whose views were denied. It's assumed that most likely they are afraid to say is unethical or they believed that is ethical but they boycott. Hence, a huge gape in the literature and indeed, for the relevant authorities to find out is why people refuse or evade paying taxes?

Table 6. WHAT BENEFIT HAVE YOU ENJOYED FROM GOVERNMENT EXPENDITURE?

\begin{tabular}{|c|c|c|}
\hline Responses & Respondents & $\mathbf{\%}$ \\
\hline Specific (e.g. loan) & 30 & 15 \\
\hline amenities (General) & 20 & 10 \\
\hline None at all & 150 & 75 \\
\hline Total & $\mathbf{2 0 0}$ & $\mathbf{1 0 0 \%}$ \\
\hline
\end{tabular}

Source: Author Generated.

Results in the above table showed that most of the respondents bitterly complained that government is not doing enough tangibly for the masses talk less of specific benefits. Some of the respondents posited that government functionaries are just sharing the revenues for personal use. This might have resulted in the peoples' avoiding taxes and breaking laws and regulations governing the practices.

Table 7. WHY ARE YOU NOT PAYING TAX AND YOU AGREED IS ETHICAL?

\begin{tabular}{|c|c|c|}
\hline Responses & Respondents & $\mathbf{\%}$ \\
\hline Bad Governance & 150 & 75 \\
\hline Religious factors & 20 & 10 \\
\hline Socio cultural & 30 & 15 \\
\hline Total & $\mathbf{2 0 0}$ & $\mathbf{1 0 0} \%$ \\
\hline
\end{tabular}

Source: Author Generated.

It is well understood from the conversation with participants and presented in the table above that even though paying tax is believed to have been ethical but still individuals (Surveyed) are not paying, in fact $75 \%$ attributes that to nonperformance by the government in all sector. This is to say, people are not convince even if they pay taxes the money will be use accordingly. Hence, significant part of the participants asserted that the bad governance resulted from mismanagement of accrued fund and corruption within the departments. Religious factor is one of the reason participants attributed to peoples' attitude of evading tax. Therefore, $10 \%$ hold this position. Lastly, $15 \%$ attributed socio-cultural reasons for their refusal to meet tax obligations.

TABLE 8. HOW DO YOU MANAGE IN SOME DEALINGS WITHOUT TAX CLEARANCE CERTIFICATE?

\begin{tabular}{|c|c|c|}
\hline Responses & Respondents & $\mathbf{\%}$ \\
\hline Fake issued & 150 & 75 \\
\hline On Request & - & - \\
\hline Bribery & 40 & 20 \\
\hline It has no usage & 10 & 5 \\
\hline Total & $\mathbf{2 0 0}$ & $\mathbf{1 0 0} \%$ \\
\hline
\end{tabular}

Source: Author Generated. 
Seen from the above table, $75 \%$ of respondents indicated the extent of dishonest staff existing within tax authorities, as participants reported that fake certificate is issued by the tax administrators in return of money collected on negotiations. This is a big indicative of extent of corruption both from the tax payers and tax collectors. In fact, additional 20\% participants indicated that they offered bribery in place of tax clearance certificate and that government officials compromise the legal requirements and aid them to evade their tax obligations. Nonetheless, the remaining $5 \%$ of the respondents asserted that they do not enter into any business dealings with official requirements.

\section{Hypothesis and Hypothesis Testing}

Using the null hypothesis previously formulated, spearman rank order correlation analysis could be employed to test the relationship between ethics of tax evasion and bad governance using some responses.

$\mathrm{H}_{0}$ : ETHICS OF TAX EVASION WAS NOT SIGNIFICANTLY INFLUENCED BY GOVERNMENT PERFORMANCE

\begin{tabular}{|c|c|c|}
\hline Responses & $\begin{array}{c}\text { Y (Performance } \\
\text { of Govt.) }\end{array}$ & $\begin{array}{c}\text { X (Ethics of Tax } \\
\text { Evasion) }\end{array}$ \\
\hline Traders & 49 & 50 \\
\hline Transporters & 35 & 40 \\
\hline Portable water producers & 45 & 45 \\
\hline Others & 21 & 45 \\
\hline
\end{tabular}

Source: Author Generated

The statistic rho $(\mathrm{r})=1-\frac{6 \sum R\left(X_{I}\right)-R\left(Y_{I}\right)^{2}}{n\left(n^{2}-1\right)}$

\begin{tabular}{|c|c|c|c|c|c|}
\hline $\mathbf{X}$ & $\mathbf{Y}$ & $\mathbf{R}\left(\mathbf{X}_{\mathbf{I}}\right)$ & $\mathbf{R}\left(\mathbf{Y}_{\mathbf{I}}\right)$ & $\mathbf{R}\left(\mathbf{X}_{\mathbf{I}}\right)-\mathbf{R}\left(\mathbf{Y}_{\mathbf{I}}\right)$ & $\mathbf{D}^{\mathbf{2}}$ \\
\hline 49 & 50 & 4 & 4 & 0 & 0 \\
\hline 35 & 40 & 2 & 1 & 1 & 1 \\
\hline 45 & 45 & 3 & 2.5 & 0.5 & 0.25 \\
\hline 21 & 45 & 1 & 2.5 & -1.5 & 2.25 \\
\hline & & & & $\mathrm{d}^{2}$ & 3.5 \\
\hline
\end{tabular}

Source: Author Generated

$$
\text { Rho } \begin{aligned}
(\mathrm{r}) & =1-\frac{6 \sum R\left(X_{I}\right)-R\left(Y_{I}\right)^{2}}{n\left(n^{2}-1\right)} \\
& =1-\frac{6(3.5)}{4(16-1)}=1-\frac{21}{60}=1-0.35 \\
& =0.65
\end{aligned}
$$

This shows a significance relationship (correlation) between government performance and ethics of tax evasion.

Let us now examine the strength of this positive correlation by converting the rho value of 0.65 to $t-$ scores

$$
\text { Using } \begin{aligned}
\mathrm{t} & =\sqrt{\frac{n-2}{1-R S^{2}}} \\
& =\sqrt{\frac{4-2}{1-(0.65)^{2}}}=\sqrt{\frac{2}{1-0.4225}} \\
& =\sqrt{\frac{2}{0.5775}}=\sqrt{3.463}=1.86
\end{aligned}
$$

Using Degree of Freedom of 2 (n- 2- $4-2)$

At the critical value of $\alpha=10 \%$ i.e. 95 level of significance is 6.965

Decision $=$ Reject $\mathrm{H}_{0}$ at 0.10 and accept

$\mathrm{H}_{1}$ : that is there is a direct positive relationship between ethics of tax evasion and government performance

\section{Conclusions}

At this juncture it can be concluded from all the arguments of different researchers as reviewed in the second section of the paper, analyses and discussions of the results in the preceding section with the help of the two statistical tools employed, it appears that there is a significant (positive) relationship between the perception of self-employed individuals on why they evade tax and the poor performance of government, thus, respondents agreed that ethically is good to pay tax but they remained noncontributory population to the national development and further argued that, mismanagement of public fund, corruption and malpractices that amounted to bad governance resulted their actions and persistent tax evading attitude. Hence, the findings of the study are summarized in the following sentences:

1. Although is ethical to pay tax but individual refuse to, due to bad governance and other factors(religious, political and socio cultural).

2. There is a high level of illiteracy in the informal sector.

3. Most of the self-employed individuals do not even file returns to relevant tax authorities.

4. Existence of dishonest tax administrators within the system contributed in tax evading.

5. There are fake tax clearances certificate in circulation issued by relevant authorities.

6. Individuals in the informal sector enjoyed less from the government entrepreneurial development policies (e.g. Loan. Capacity Building etc.).

7. Self-employed individuals spend most of their times in business

Having seen the afore-discussed findings of the study, it is recommended the future research relating to tax issues should look into general economic sector of Bauchi State instead of limiting the scope to informal sector. This will help in making suggestions and recommendations to policy makers as well as the state government in general. Indeed, it will give an opportunity to a wide range of stakeholder groups to contribute or participate in the study.

\section{References}

[1] Ayua L. A. (1999). The Nigerian Tax Law. Ibadan. Spectrum Law Publishing.

[2] Boyland A. and Burckhardt T. (2002) "Buriers in SelfEmployment for Disable People. Available at: www.berr.gov.uk/files/files38359.Accessed on 21/05/2014.

[3] Brunetti A. and Wader A. (2003) A Free Is Bad News for Corruption: Journal of Public Economics. Vol. 97, Pp. 180182.

[4] Chiuma C. (2006) Counteracting Tax Evasion in Malawi: An Analysis of the Method and Quest for Improvement. Munich Personal Archive. Pp. 1-42.

[5] Dandago K.I and Alabde J. O (2000) Taxation and Tax Administration in Nigeria, Kano; Triumph Publishing Co. Ltd, Kano, Nigeria. 
[6] Ebozieybe M. O (2007) Tax Evasion Hinders Local Government. The Saturday Tribune, October 13, 2009.

[7] Eigen P. (2002) Measuring and Combating Corruption. Journal of Policy Reforms. Vol. 5. Pp. 187-201.

[8] Ekpo I. and Umoh, J.(1996) Operations of informal sector in Nigeria; Challenges and prospects: http//:www.onlinenigeria.com

[9] Ezeoha, A. E, Ogamba, E. (2010) Corporate Tax Shield or Fraud? Insight from Nigeria. International Journal of Law and Management. Vol, 52(1), 5-20.

[10] Faruyola G. O (1987) Guide to Nigerian Taxes Lagos: All Crown Nigeria. Ltd.

[11] Feld L. P and Frey B. S (2002) Trust Breed Trust: How Taxpayers Are Treated. International Journals of Economics and Governance. Vol. 3, Pp 87-99.

[12] Kay G. (1980) The Anatomy of Tax Avoidance in Income Distribution: Limits to Redistribution Proceeding of the $31^{\text {st }}$ Symposium of the Colstor Research Society, University of Bristol, John Write and Sons Ltd. Pp.135-1484.

[13] Kiabel B. D and Nwankwo N. G (2009) Curbing Tax Evasion and Avoidance in Personal income. Owerri Springfield Publishers

[14] Kiable B.D (2001) Personal Income Tax in Nigeria. Owerri Springfield Publishers.

[15] Norman, L. (1999) World Bank Policy Research WP No. 1727 Nov, 301999.

[16] Nwachukwu I. (2006) Institutions Indulge in Tax Evasion Despite Huge Profit they Make in Nigerian. The Tribune, September, 1, 2006.

[17] Olatunde J. O (2009) Tax Evasion, Tax Avoidance and Corruption: An Interface with Source of Finance for Development in Nigeria. Journal of Critical and Applied Economics: Romania.
[18] Oluyinka M. U. Temitope, O. F and Jumoke, O. O (2010) An Empirical Study of the Relationship between Culture and Personal Income Tax in Nigeria European Journal of Economics, Finance and Administrative Science. Issue 20.

[19] Onuihbo O. (1986) Banking and Finance for Professional Examination: Aba, Nigeria Yonkee Standard Press Ltd.

[20] Scheinder F. and Enste D. (2000) Shadow Economics around the World: Size Censes and Consequences IMF Working Papers WP/00/26, Pp.1-56.

[21] Sikka P. and Hampton M. P (2005) The Role of Accountancy Firms in Tax Avoidance Some Evidence and Issues: Accounting Forum 29 (3) Pp. 325-343.

[22] Sikka P. (2008) Enterprise Culture and Accountancy Firms: New Masters of the Universe. Accounting, Auditing and Accountability Journal, Vol, 21(2), Pp. 268-95.

[23] Sikka P. and Willmott H. (2010) The Dark Side of Transfer Pricing: It's Role in Tax Avoidance and Wealth Retentiveness. Critical Perspectives on Accounting. Vol. 21(4): 342-56.

[24] Soyede L. and Kujola S. O (2006) Taxation Principle and Practice in Nigeria; $1^{\text {st }}$ Edition Silicon: Ibadan.

[25] Tax Administration: A Study of the South- South states of Nigeria "European Journal of economic, finance and administrative sciences issue 15 (2006).

[26] Toby R. (1983). The Theory and Practice of Income Tax. Macmillan Press Ltd.

[27] Uvima A. (2009) Imperative of Tax Payment Being a Paper Presented at the $1^{\text {st }}$ Akwalbom State Revenue Summit April 6, 2009. 